\title{
Exploring the potential of biopharmaceutical production by Rigidoporus ulmarius: Cultivation, chemistry, and bioactivity studies
}

\author{
Jing-Jy Cheng ${ }^{\mathrm{a}, 1}$, Huu-Sheng Lur ${ }^{\mathrm{b}, 1}$, Nai-Kuei Huang ${ }^{\mathrm{a}}$, Hsuan-Pei Chen ${ }^{\mathrm{a}}$, Cha-Yui Lin ${ }^{\mathrm{b}}$, Mei-Kuang Lu ${ }^{\mathrm{a}, *}$ \\ ${ }^{a}$ National Research Institute of Chinese Medicine, Taipei, Taiwan \\ ${ }^{\mathrm{b}}$ Department of Agronomy, National Taiwan University, Taipei, Taiwan
}

A R T I C L E I N F O

\section{Article history:}

Received 7 April 2009

Received in revised form 25 May 2009

Accepted 24 June 2009

\section{Keywords:}

Rigidoporus ulmarius

Polysaccharides

Nucleoside

Antiangiogenesis

Anti-inflammation

\begin{abstract}
A B S T R A C T
Rigidoporus ulmarius is used as a medicinal fungus in Asia. Three isolates (denoted \#61, \#62, and \#63) of $R$. ulmarius were collected, and their biological activities were evaluated. Extracted polysaccharides from isolate \#63 showed greater inhibition activity compared to isolates \#61 and \#62 in an in vitro endothelial cell tube formation assay, a standard evaluation of angiogenesis. The polysaccharides and ethanolic extract of isolate \#63 dose-dependently suppressed the production of the interferon (IFN)- $\gamma$-induced inflammation marker, IP-10. Chemical analyses of the polysaccharides revealed that isolate \#63 contained the highest value of fucose at a concentration of $59.1 \pm 1.2 \mu \mathrm{mol} / \mathrm{g}$ polysaccharide. These results suggest that fucose-containing polysaccharides may play a role in the inhibitory effect. Isolate \#63 showed the highest values of ADP among the three isolates in the ethanolic extract. These results suggest that different isolates from $R$. ulmarius exhibit different abilities to regulate antiangiogenic and anti-inflammatory processes.
\end{abstract}

(C) 2009 Elsevier Ltd. All rights reserved.

\section{Introduction}

Mushrooms are well known and have been used for many years in Oriental populations as teas, nutritional foods, and even drugs. They exhibit special fragrances and textures [1]. Their biochemical composition consists mainly of proteins, carbohydrates, lipids, and vitamins. Fungal polysaccharides as biomaterials have found a wide range of applications including use in pharmaceutical therapy due to their unique physiological activities. Another advantage of obtaining bioactive polysaccharides from cultured mushrooms is the obvious potential for higher mycelial production in a compact space and in a shorter time with fewer chances for contamination. Basidiomycetes are the most used class as food due to their low toxicity to man, and they have extensively been studied. Despite their origin, the antitumor effects are generally attributed to polysaccharides with $1,3-\beta$-glucan structures [2] or a $\beta$-glucan-protein complex [3]. However, the precise structure has not been fully characterized. Different physicochemical parameters of $\beta$-glucans, such as solubility, primary structure, molecular weight, extent of branching by side-chain substituents

\footnotetext{
* Corresponding author at: National Research Institute of Chinese Medicine, 155 1 Li-Nung Street, Section 2, Peitou District, Taipei 112, Taiwan.

Tel.: +886 28201999x7391; fax: +886228264276.

E-mail address: mklu@mail.nricm.edu.tw (M.-K. Lu).

1 These authors contributed equally to this work.
}

[4], and the charge on the polymer, all appear to influence their biological activities [5].

For many years, interest has concentrated on polysaccharides produced by mushrooms as potentially useful, biologically active ingredients for pharmaceutical applications as anticoagulants [6], antibiotics [7], and vaccines [8] due to a variety of biological activities, such as mitogenic activity, activation of alternative pathway complement (APC), an anti-hepatitis B surface antigen effect, anti-inflammation, plasma clotting activity, and tumorsuppressive effects. The mushroom, Rigidoporus ulmarius, of the Polyporaceae, is found mainly on broadleaf trees. The fruiting bodies are white, yellowish to rose pink color, and rigid after dryness. It has long been used as a traditional medicine in Asia. Our previous serial study showed that fungal polysaccharides play important roles in regulating angiogenesis [9]. Angiogenesis is a dynamic process of endothelial proliferation and differentiation. Tumors with high angiogenic activity have been correlated with poor patient survival [10-12]. Therefore, fungal polysaccharides can be a useful adjunct to conventional cancer therapies. Interferon-gamma (IFN- $\gamma$ ) has been demonstrated to be a key cytokine involved in inflammatory processes. IFN- $\gamma$ induces the JAK/STAT1 signaling pathway in endothelial cells (ECs) followed by induction of chemokines which serve as chemotactic factors to recruit $\mathrm{T}$ cells to sites of inflammation then induce atherosclerotic lesions. CXCL10 (IP-10) is the major chemokine induced after IFN- $\gamma$ release [13-15]. However, there is no other documentation of its biological functions or chemical constituents. It would be interesting and worthwhile to investigate 
the chemical components and biological functions of $R$. ulmarius. In an attempt to assess the potential usage of $R$. ulmarius, in vitro experiments were first conducted with mycelial extracts of three $R$. ulmarius isolates to verify their biological functions. Therefore, in this study, we monitored the effects of endothelial tube formation to identify their actions on angiogenesis, IP-10 release to identify their actions on inflammation, and the biological correlations with the chemical components of the R. ulmarius extracts.

\section{Materials and methods}

\subsection{Materials}

R. ulmarius isolates \#61 (TFRI \#1047) and \#62 (TFRI \#1047 MG) were isolated from fruiting body collected from South of China (Fu-Jian) on April 2002, and \#63 (TFRI \#1058) was isolated from fruiting body collected from Northern Taiwan (FuShan Research Station) on February 2002. High-performance liquid chromatographic (HPLC) standards, ADP (97\%), cytidine (99\%), adenosine (99\%), inosine (99\%), myo-inositol (99\%), sorbitol (98\%), fucose (99\%), galactosamine (99\%), glucosamine (99\%), galactose (99\%), glucose (99.5\%), mannose (99\%), and fructose (99\%) were purchased from Sigma (Saint Louis, MO, USA).

\subsection{Liquid culture}

R. ulmarius was cultured in $100 \mathrm{ml}$ of $24 \mathrm{~g} / \mathrm{L}$ potato dextrose broth (PDB), with $20 \mathrm{~g} / \mathrm{L}$ glucose $\mathrm{pH} 5.6$ at $28^{\circ} \mathrm{C}$. A 35-day-old culture was harvested for polysaccharides and ethanolic extraction. PDB and glucose were purchased from Sigma (Saint Louis, MO, USA). LC-grade organic solvents were purchased from Merck (Darmstadt, Germany).

\subsection{Preparation of polysaccharides and the ethanolic extract}

Polysaccharides were isolated from lyophilized mycelia by hot water at $80{ }^{\circ} \mathrm{C}$ in a $1: 100(\mathrm{w} / \mathrm{w})$ ratio for $6 \mathrm{~h}$ twice and cooled, and then four volumes of $95 \%$ ethanol were added and precipitated overnight at $4{ }^{\circ} \mathrm{C}$. The precipitated polysaccharides were collected by spinning at $9000 \times \mathrm{g}$ for $20 \mathrm{~min}$ and lyophilized, resulting in a crude polysaccharide sample. The ethanolic supernatant was lyophilized following centrifugation and was denoted the ethanolic extract.

\subsection{Endothelial cell culture}

ECs were cultured under condition as described before [13]. Briefly, endothelial cells were maintained in DMEM medium (Life Technologies) supplemented with $2 \mathrm{mM}$ L-glutamine and 10\% heat-inactivated fetal bovine serum (FBS) (Life Technologies) under standard culture conditions. The cell viability and cell numbers were determined by the trypan blue dye-exclusion method.

\subsection{MTT assay}

Measurement of cellular 3-(4,5-dimethyl thiazol-2-yl)-2,5-diphenyl-tetrazolium bromide) (MTT) reduction was performed as described previously [16]. The result of absorbance of MTT-formazan adducts is shown as the percentage of untreated control cells to indicate percentage of surviving cells.

\subsection{Matrigel EC tube formation assays}

In vitro Matrigel tube formation was performed as previously described [17]. The tube formation area, length, joints, and branches were expressed as percentages of the VEGF-treated controls using KURABO Angiogenesis Image Analysis Software.

\subsection{Detection of IP-10 protein release}

Levels of IP-10 secreted into the culture supernatant collected from ECs after IFN$\gamma$ stimulation with or without pretreatment with $R$. ulmarius polysaccharides or the ethanolic extract were determined using a sandwich enzyme-linked immunosorbent assay (ELISA) kit (R\&D Systems, Minneapolis, MN, USA) according to the manufacturer's instructions. Concentrations of secreted IP-10 were determined using ELISA readers from BioSource (Camarillo, CA, USA).

\subsection{Size-exclusion chromatography (SEC) of polysaccharides}

SEC measurements were performed at room temperature on two SEC columns (G4000PW $\mathrm{XL}_{\mathrm{XL}} 7.8 \mathrm{~mm} \times 300 \mathrm{~mm}$ and G3000PW $\mathrm{XL}_{\mathrm{XL}} 7.8 \mathrm{~mm} \times 300 \mathrm{~mm}$, Viscotek). The flow rate was $0.5 \mathrm{ml} / \mathrm{min}$, with deionized water was used as the eluent. An RI detector (Viscotek model 301) was used. A polysaccharide solution in milli-Q water was diluted to give a concentration of $1 \mathrm{mg} / \mathrm{ml}$. The sample injection volume was $0.1 \mathrm{ml}$. Calibration was performed against an authentic standard, Sodex P-82 series (Showa Denko, Mentor, OH) containing polymaltotriose with molecular weights of $788,404,212,112,47.3,22.8,11.8$ and 5.9 kilodaltons (kDa).

\subsection{Compositional analysis of polysaccharides}

Acid hydrolysis of polysaccharides and determination of monosaccharides composition were carried out according to Cheng et al. [17]. Monosaccharides were identified by comparing retention times of sample peaks with those of standards. Quantification of each monosaccharide was carried out by integration of the chromatographic peak on a PeakNet system (Dionex, Sunnyvale, CA). Standards of monosaccharide were dissolved in Q-water. Myo-inositol, sorbitol, fucose, galactosamine, glucosamine, galactose, glucose, and mannose were obtained from Sigma (Saint Louis, MO, USA). Sodium hydroxide solution was obtained from Fisher Scientific (Pittsburg, PA, USA).

\subsection{High-performance liquid chromatographic (HPLC) analysis of the ethanolic} extract

Nucleoside and nucleotide were identified by comparing retention times and photodiode array spectra $(200-400 \mathrm{~nm})$ of sample peaks with those of standards. Quantification of each nucleoside and nucleotide was carried out by integration of the chromatographic peak. Separations were carried out according to Cheng et al [17] and modified as follows: standards were dissolved in $0.02 \mathrm{M} \mathrm{NaH}_{2} \mathrm{PO}_{4}, \mathrm{pH}$ 7.0. Samples were dissolved in $50 \%$ methanol.

\subsection{Statistical analysis}

Statistical analysis was performed using Student's $t$-test. Data are presented as the mean \pm SEM. Statistical significance was defined as $p<0.05$.

\section{Results}

\subsection{The growth and polysaccharide production of $R$. ulmarius}

Mycelia of R. ulmarius of isolate \#61 cultured by PDB as carbonsourced medium was shown (Fig. 1A). The culture period between 7 and 28 days was a linear phase. Beyond 28 days, the culture entered a senescence phase. The time-course study of the polysaccharide yield showed that at 21 days of culture, the highest value of $0.74 \pm 0.07 \mathrm{~g} / \mathrm{L}$ was achieved (Fig. 1B). Comparisons
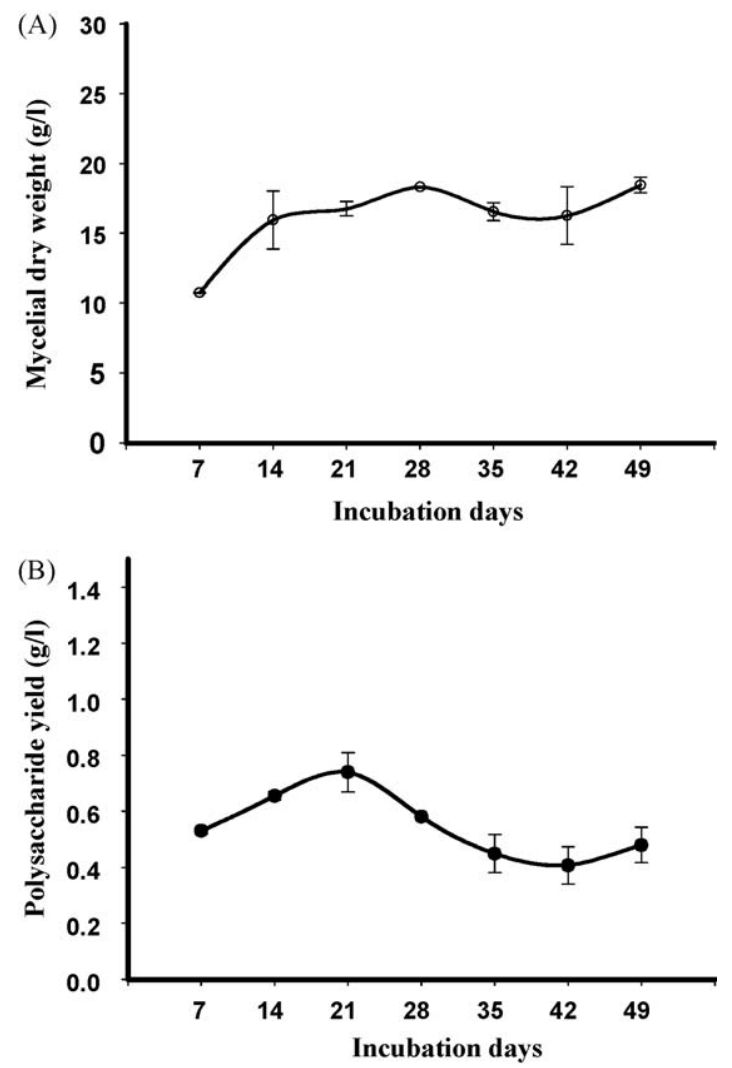

Fig. 1. Time course of growth and polysaccharide production in a mycelial culture of Rigidoporus ulmarius isolate \#61. (A) Growth; (B) polysaccharide yield. Data are presented as the mean \pm S.E. from three independent experiments. 

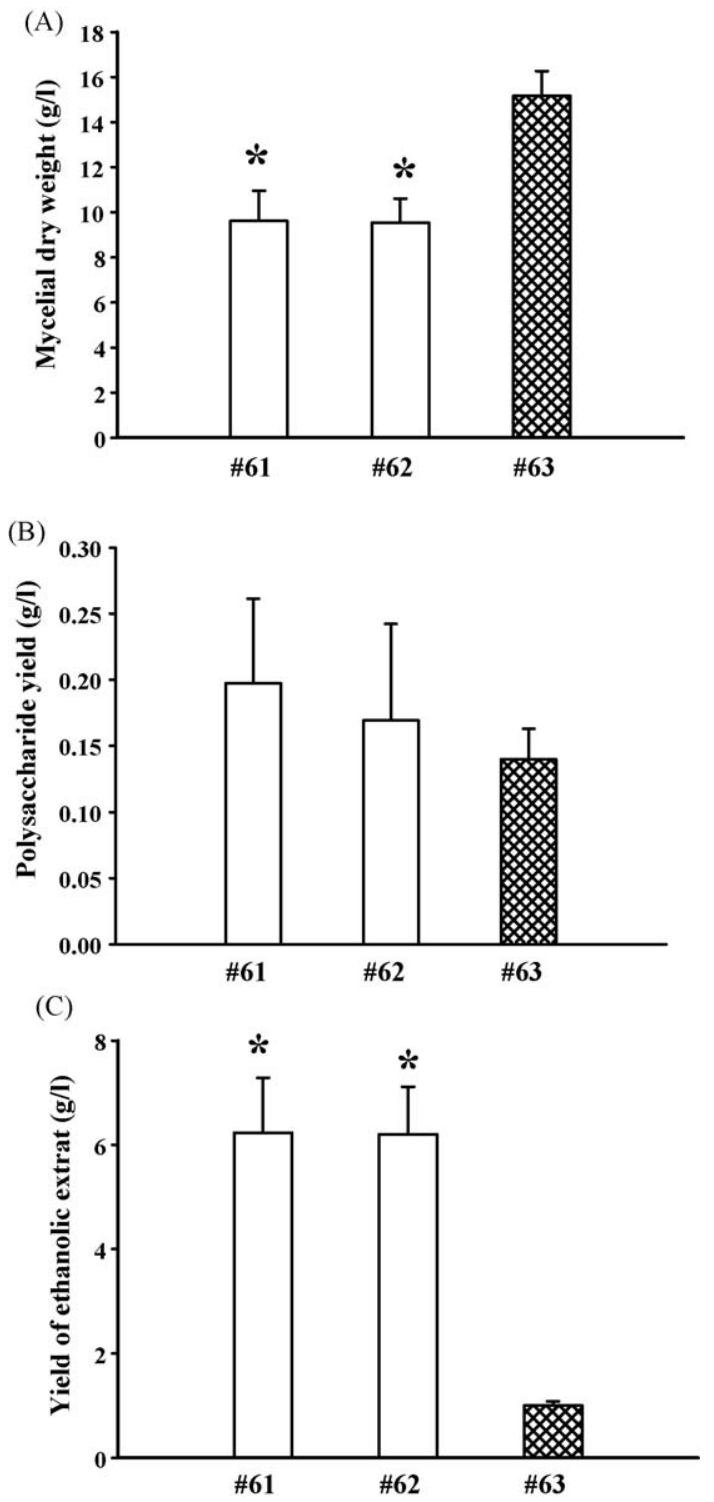

Fig. 2. Comparisons of yield of growth, polysaccharide and ethanolic extract production in a mycelial culture of among three isolates of Rigidoporus ulmarius. (A) Dry weight; (B) polysaccharides; (C) ethanolic extract. Data are presented as the mean \pm S.E. from three independent experiments. ${ }^{*} p<0.05$ vs. isolate \#63.

were made of the dry weight (Fig. 2A), polysaccharides (Fig. 2B), and ethanolic extract production (Fig. 2C) of 35-day cultures among the three isolates. Isolates \#63 showed the highest dry-mass accumulation and the lowest ethanolic extract production among the three isolates. Isolates \#61 and \#62 showed no significant differences in growth, polysaccharides, or ethanolic extract production.

\subsection{Toxicity of R. ulmarius}

MTT assay was performed to evaluate the toxicity of $R$. ulmarius polysaccharides and the ethanolic extract toward EC. Confluent ECs was changed to serum-free medium and a serial dilution of polysaccharides and ethanolic extract were used to evaluate the toxicity toward ECs for $24 \mathrm{~h}$. Neither the polysaccharides nor the ethanolic extract showed any toxicity toward ECs up to a concentration of $1000 \mu \mathrm{g} / \mathrm{ml}$, except for the ethanolic extract of \#63 at the concentration of $1000 \mu \mathrm{g} / \mathrm{ml}$ showed slightly degree of cytotoxicity (Table 1 ).

\subsection{Influences of R. ulmarius on EC tube formation}

In vitro Matrigel tube formation model for evaluation of angiogenesis were performed to study the effects of fungal polysaccharides and the ethanolic extract. Several parameters for determining antiangiogenic efficiency was checked for EC tubelike structures by calculating number of pixels in presenting total vascular area ratio, vascular length, and branching numbers. The area ratio was calculated by the area of tube formation/the field of vision. The smaller the value is, the lesser the degree of tube formation (the higher degree of inhibition of angiogenesis). Serial dilutions were used to study for their effects on VEGF-induced Matrigel tube formation (Fig. 3). The tube formation area ratio, and the ratio of tube length, joints, and branches all indicated a dose-dependent effect of inhibiting angiogenesis with polysaccharide pretreatment. Among the three fungal polysaccharides, \#61 and \#62 showed moderate inhibition of tube formation. The fungal polysaccharides of \#63 showed the highest degree of inhibition of endothelial tube formation. These results indicate that polysaccharides of isolate \#63 can be an angiogenesis inhibitor.

\subsection{Influences of $R$. ulmarius on IFN- $\gamma$-induced IP-10 secretion}

Pretreatment of polysaccharides or the ethanolic extract isolated from $R$. ulmarius were evaluated for their inhibitory effects on IP-10 protein release induced by IFN- $\gamma$. As shown in Fig. 4, IFN- $\gamma$ treatment increased IP-10 protein release on ECs. Pretreatment of ECs with polysaccharides of isolate \#63 suppressed IFN- $\gamma$-induced IP-10 protein release in a dose-dependent manner. However, pretreatment with the ethanolic extracts of \#61 and \#62 showed no effects on IFN- $\gamma$-induced IP-10 protein release. Only pretreatment of ECs with the \#63 ethanolic extract suppressed IFN- $\gamma$-induced IP-10 protein release in a dosedependent manner. This result indicates that the different isolates

Table 1

Toxicity of R. ulmarius to endothelial cells (ECs).

\begin{tabular}{|c|c|c|c|c|c|}
\hline & \multicolumn{5}{|c|}{ Cell viability (\% of control) } \\
\hline & $20^{a}$ & $100^{\mathrm{a}}$ & $250^{\mathrm{a}}$ & $500^{a}$ & $1000^{\mathrm{a}}$ \\
\hline \multicolumn{6}{|c|}{ Polysaccharides } \\
\hline \#61 & $118.65 \pm 6.19$ & $111.31 \pm 8.75$ & $121.14 \pm 12.50$ & $121.59 \pm 12.08$ & $123.28 \pm 12.71$ \\
\hline \#62 & $118.05 \pm 8.49$ & $108.03 \pm 9.37$ & $126.49 \pm 11.93$ & $133.71 \pm 18.49$ & $114.56 \pm 9.39$ \\
\hline \#63 & $116.00 \pm 11.44$ & $103.85 \pm 7.90$ & $134.42 \pm 13.91$ & $138.10 \pm 21.04$ & $115.99 \pm 9.73$ \\
\hline \multicolumn{6}{|c|}{ Ethanolic extract } \\
\hline \#61 & $103.90 \pm 6.60$ & $113.23 \pm 3.58$ & $117.82 \pm 3.09$ & $117.83 \pm 8.00$ & $127.20 \pm 14.78$ \\
\hline \#62 & $118.18 \pm 8.55$ & $122.96 \pm 7.26$ & $137.55 \pm 24.07$ & $131.77 \pm 14.08$ & $119.05 \pm 13.81$ \\
\hline \#63 & $112.96 \pm 9.67$ & $117.47 \pm 12.01$ & $134.69 \pm 8.61$ & $122.57 \pm 8.26$ & $87.11 \pm 4.59$ \\
\hline
\end{tabular}

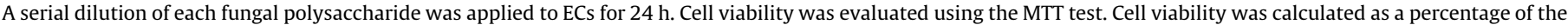
control from three separate experiments.

a Concentration $(\mu \mathrm{g} / \mathrm{ml})$. 


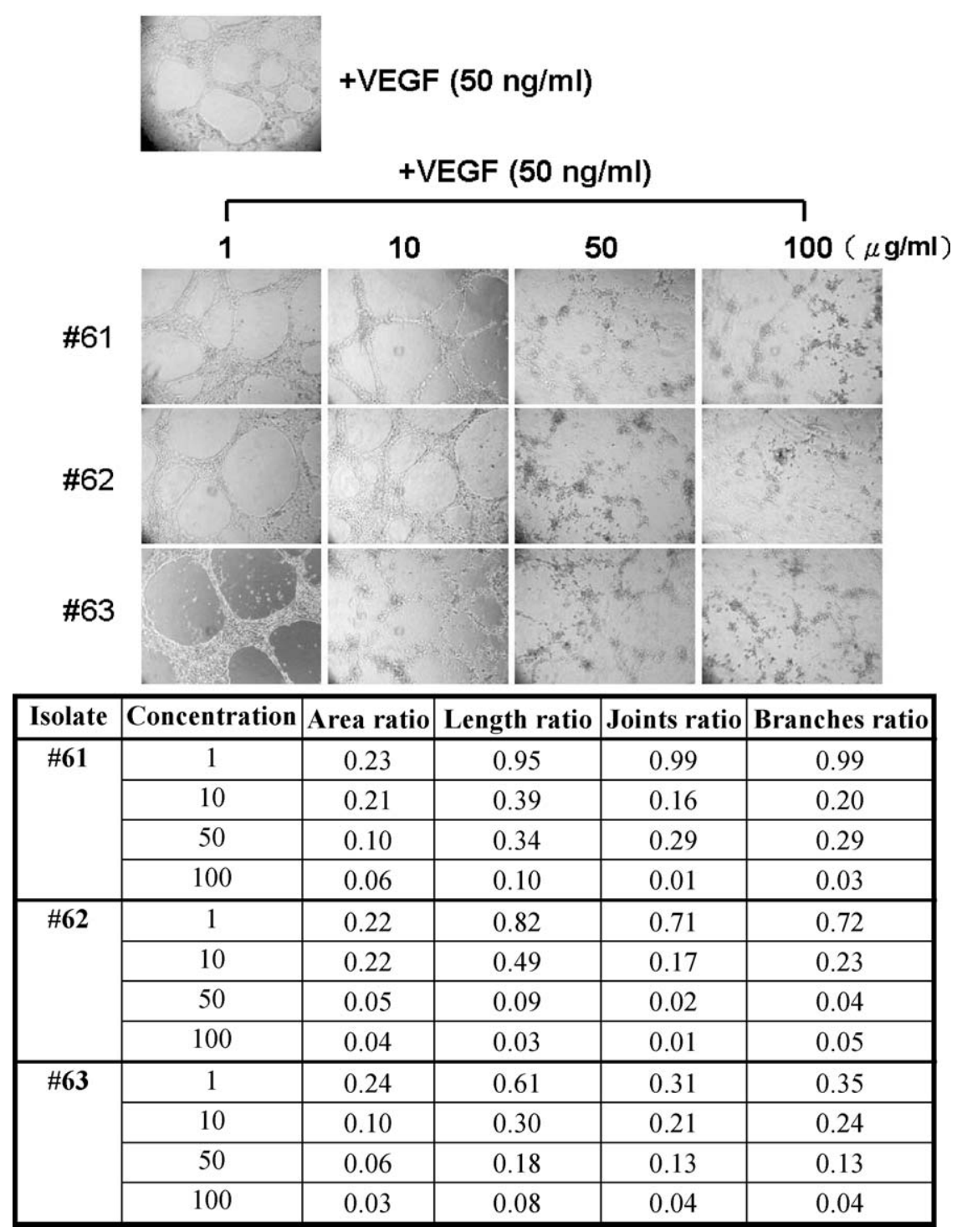

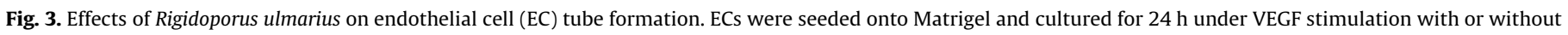

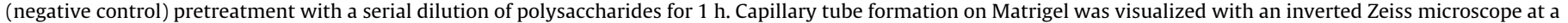

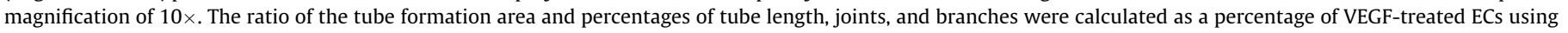
KURABO Angiogenesis Image Analysis Software as indicated in the lower panel.

of $R$. ulmarius or different extracts of the same isolate may exhibit different levels of anti-inflammatory effects.

\subsection{Characteristics of polysaccharides}

To study the relationships between the structure and biological function of these polysaccharides, the polysaccharides were characterized according to their molecular size distributions and sugar compositions. The molecular weight distribution of the lyophilized polysaccharide-containing preparation was determined by size-exclusion column chromatography (Fig. 5). A calibration curve was constructed using a series of standards containing polymaltotriose with molecular weights of 788,404 , $212,112,47.3,22.8,11.8$ and 5.9 kilodaltons $(\mathrm{kDa})$. The regression equation was made between the $\log [\mathrm{Mw}](Y)$ and the fraction number $(X)$ as $Y=9.34-0.24 X ; R^{2}=0.99419$. The molecular weight distributions were characterized as very high molecular weight ( $>2000 \mathrm{kDa}$, peak 1 ), high molecular weight ( $>400 \mathrm{kDa}$, peak 2), medium high molecular weight ( $>100 \mathrm{kDa}$, peaks 3 ), low molecular weight $(>7 \mathrm{kDa}$, peaks 4$)$, and very low molecular weight $(<1 \mathrm{kDa}$, peak 5$)$. The results showed that the very high molecular weight (peak 1) and very low molecular weight (peak 5) contributed equally and represented the major species in the total polysaccharides of isolates \#61 and \#62. The molecular weight distribution of \#63 differed from those of the others in the lack of the very high molecular weight (peak 1) of $2300 \mathrm{kDa}$, which accounted for $55.2 \%$ of total polysaccharides, and of very low molecular weight (peak 5) polysaccharides.

The chemical compositional of polysaccharides was obtained after the polysaccharide fraction had been completely hydrolyzed. The carbohydrate chromatogram (Fig. 6) and composition is presented in Table 2. The results showed that fucose, glucose, mannose, and fructose were the dominant sugars in the polysaccharides. Comparisons were made among the three isolates. Isolate \#63 contained the highest value of fucose at a concentration of $59.1 \pm 1.2 \mu \mathrm{mol} / \mathrm{g}$ polysaccharide.

\subsection{Chemical composition of the ethanolic extracts from R. ulmarius}

The R. ulmarius ethanolic extracts were separated by HPLC. Components were eluted from the column with mixtures of acetonitrile and $\mathrm{NaH}_{2} \mathrm{PO}_{4}$ and analyzed by UV detection at $260 \mathrm{~nm}$. 

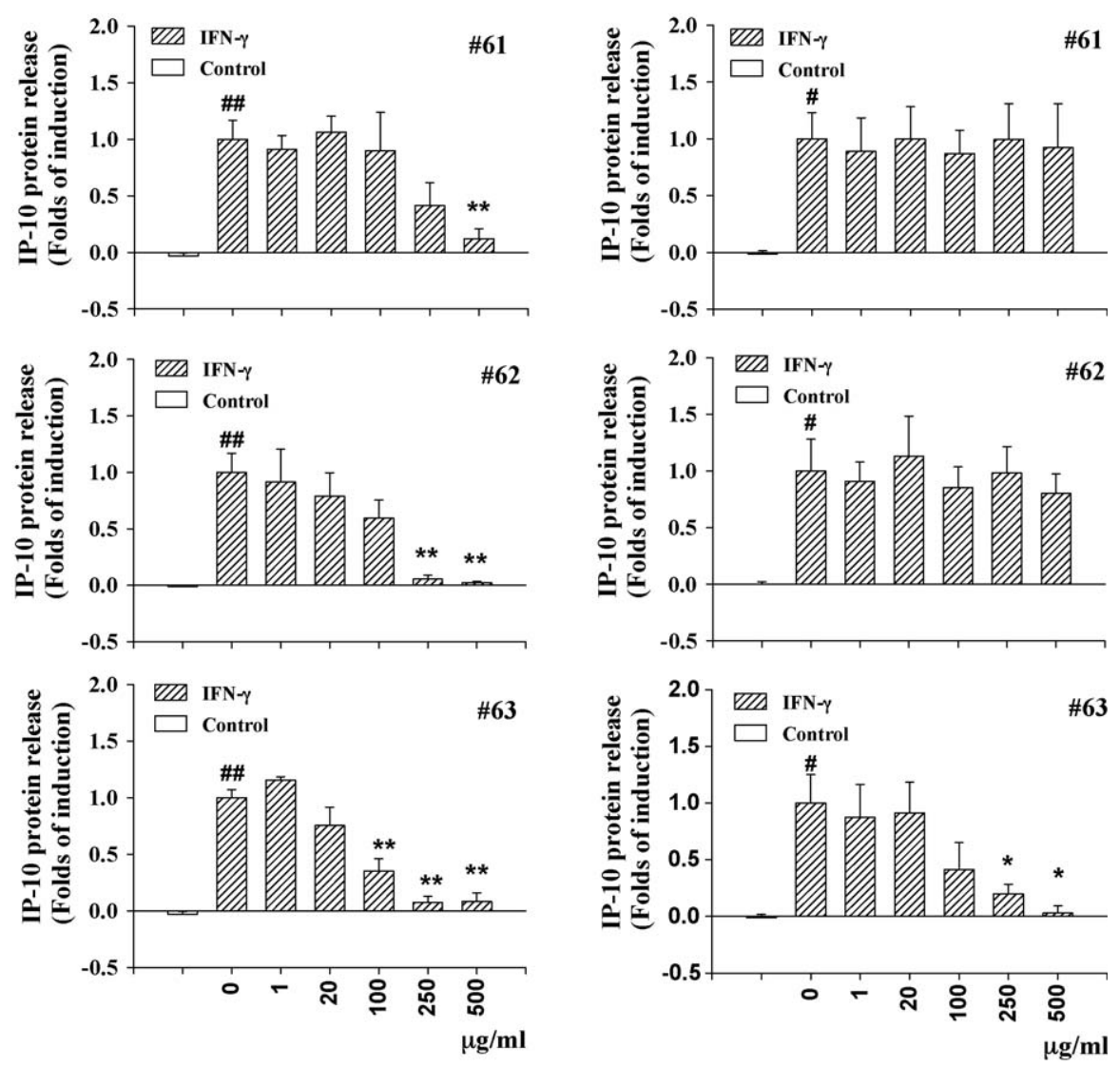

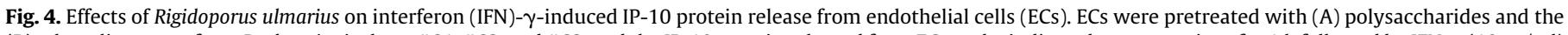

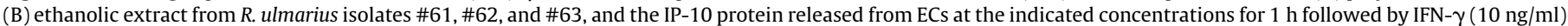

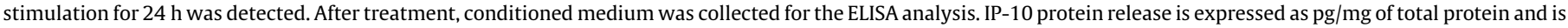
presented as the mean \pm S.E. from three independent experiments. ${ }^{*} p<0.05,{ }^{* *} p<0.01 \mathrm{vs}$. IFN- $\gamma$ treatment; ${ }^{*} p<0.05$, ${ }^{\# \#} p<0.01$ vs. the control.

The separation chromatogram (Fig. 7) and the data are shown in Table 3. Three nucleoside-type compounds were identified. Isolate \#63 had the highest values of ADP at $6.61 \pm 0.19 \mathrm{mg} / \mathrm{g}$ ethanolic extract.

\section{Discussion}

Polysaccharides are of great interest from both an ecological perspective and human health demands. They also play important roles for the fungus itself as primary metabolites. There is growing interest in their use as pharmaceuticals. It is interesting to use an in vitro system to improve the production of these compounds. Also in the middle of the 20th century, improvements in analytical techniques such as chromatography allowed the successful identification of these macromolecules. Polysaccharides of the mushroom, $R$. ulmarius, used in this study were previously shown to exhibit antiangiogenic activity [16]. Different sources of mushrooms from nature are expected to produce different isolates with different chemical texture, for example, polysaccharides differing somewhat in structures, and compositions $[18,19]$. These different chemical compositions may lead to different biofunctions of this fungus. Therefore, this article describes the characteristics of different isolates of $R$. ulmarius and its bioactivities so that it can be developed as a potential food supplement and for therapeutic uses.

Due to the difficulty in collecting sufficient quantities of the remedy in the wild, we successfully used established liquid culture methods to acquire mass-produced cellular material from cultured mycelia. These mycelia cultures allowed us to evaluate the possible mechanisms underlying the antiangiogenic, and anti-inflammatory effect. According to our results, myo-inositol, fucose, glucose, mannose, and fructose were neutral sugars in polysaccharides of $R$. ulmarius. Isolate \#63 exhibited a higher amount of fucose. In this study, the antiangiogenic activity of isolate \#63 was much higher fucose compared those of the other isolates. The amount equaled to fucose in total polysaccharides of \#63 was added and showed no significant inhibition on Matrigel tube formation (data not shown). Same observation showed that the content of fucose in the fucoidans from brown seaweeds did not significantly affect its antiangiogenic activity [20]. Although fucose was documented to be a major component involved in antiangiogenic, anti-inflammatory, anticoagulant, and anti-adhesive activities [20,21]. Mourão et al. [22] observed that sulfated fucose branches are also necessary for the anticoagulant and antithrombotic [23,24] activities of this glycosaminoglycan. In the structure feature of polysaccharides, fucose was one of the sugar components. The biological activity of polysaccharides of \#63 could be due to fucose-containing linkage in structure which may important for its activity, but not the fucose itself. Those results suggested that different bioactivities may result from different levels of conjugation from monosaccharides to polysaccharides, including the composition of the side chain, the length of the side chain, and the number of repeated individual units.

Our findings indicate that polysaccharides and the ethanolic extract of isolate \#63 showed the most potent anti-inflammatory activities. The very high molecular weight (peak 1) of $2300 \mathrm{kDa}$, accounted for $55.2 \%$ of the \#63 polysaccharides. This suggests that the proportion of polysaccharides with a high molecular weight 

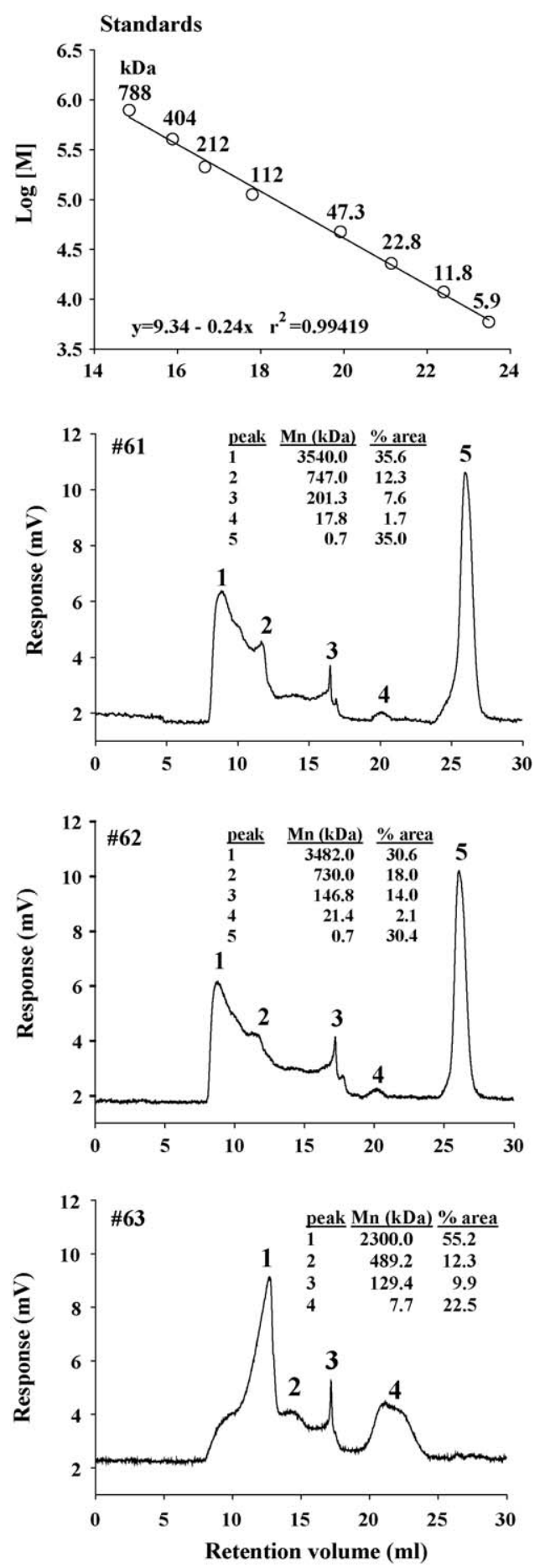

Fig. 5. Size-exclusion chromatography (SEC) profile of Rigidoporus ulmarius polysaccharides. SEC was performed using a ViscoTek model TDA-3-1 relative viscometer (Viscotek). A polysaccharide solution in milli-Q water was diluted to give a final concentration of $1 \mathrm{mg} / \mathrm{ml}$ for the determination.

( $>2000 \mathrm{kDa}$ ) affects the anti-inflammatory properties. Observations of the anti-inflammatory effect of isolate \#63 suggest that ADP in the ethanolic extract, which were much higher than those of isolates \#61 and \#62, might play roles in anti-inflammation. $\mathrm{ADP}$ and related nucleoside-based compounds are well-known intracellular constituents, intimately involved in all aspects of cell functions and act as enzyme cofactors, sources of energy, and building blocks for DNA. Currently, purinoreceptors can be subdivided into $\mathrm{P} 1$ receptors, which bind adenosine as natural ligands and P2 receptors which bind ATP and ADP [25]. At present,
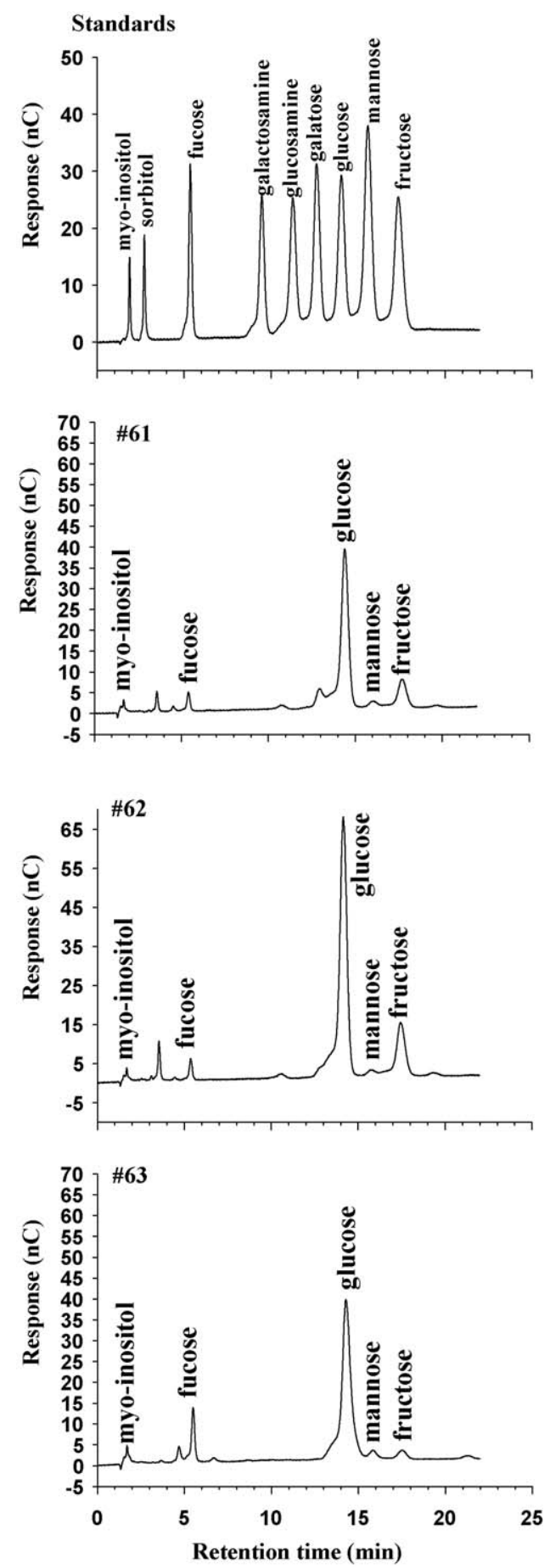

Fig. 6. High-performance anion-exchange chromatography (HPAEC) of R. ulmarius polysaccharide hydrolysates. The HPAEC analysis was carried out in $18 \mathrm{mM} \mathrm{NaOH}$ for $20 \mathrm{~min}$ at ambient temperature.

Table 2

Sugar composition of $R$. ulmarius polysaccharides.

\begin{tabular}{|c|c|c|c|c|c|}
\hline \multirow[t]{2}{*}{ Isolates } & \multicolumn{5}{|c|}{$\mu \mathrm{mol} / \mathrm{g}$ polysaccharide } \\
\hline & Myo-inositol & Fucose & Glucose & Mannose & Fructose \\
\hline \#61 & $9.4 \pm 2.4$ & $20.0 \pm 3.4$ & $251.7 \pm 11.7$ & $23.1 \pm 7.9$ & $98.1 \pm 15.6$ \\
\hline \#62 & $13.1 \pm 5.3$ & $22.5 \pm 1.8$ & $453.6 \pm 9.6$ & $30.4 \pm 2.2$ & $234.7 \pm 17.2$ \\
\hline \#63 & $8.4 \pm 0.9$ & $59.1 \pm 1.2$ & $351.2 \pm 9.1$ & $18.8 \pm 0.5$ & $30.6 \pm 0.2$ \\
\hline
\end{tabular}



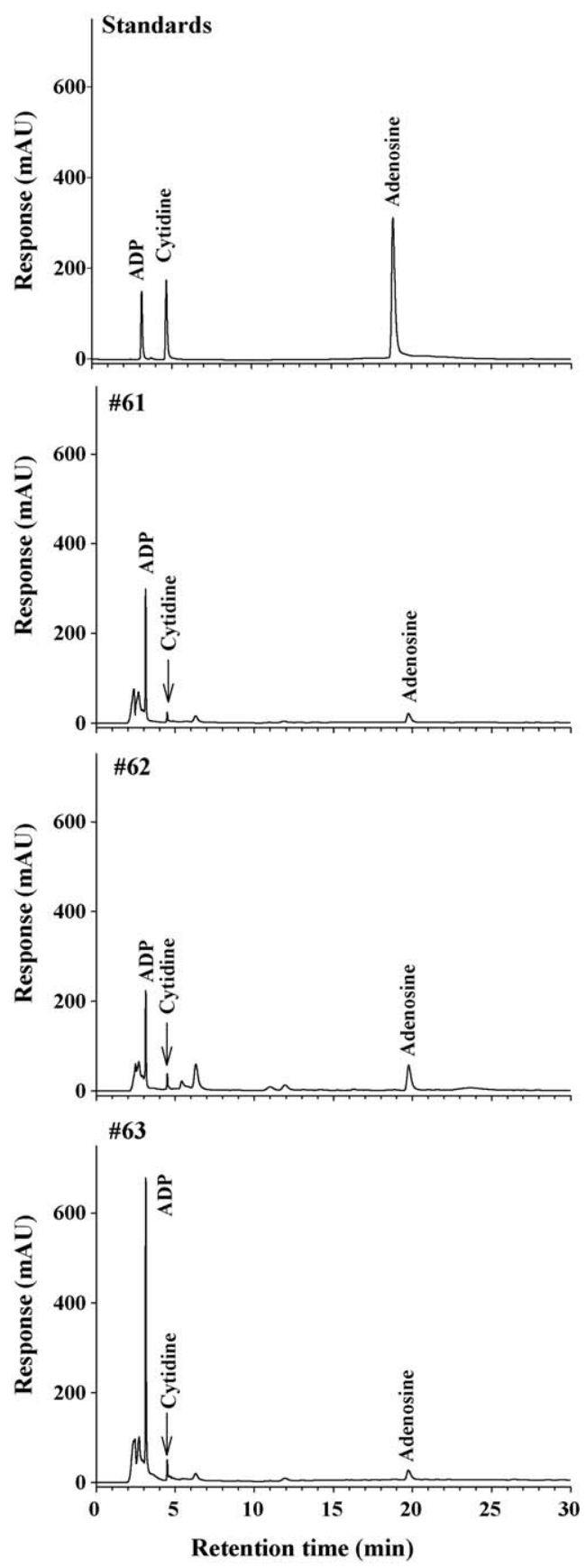

Fig. 7. High-performance liquid chromatography of $R$. ulmarius ethanolic extract.

these purinoreceptors are known to play important roles in regulating diverse physiological and pathological functions [26]. Furthermore, in comparison with our previous study that extracts from Fomitopsis pinicola [17], polysaccharides of three isolated of $R$. ulmarius in this study showed more potency than that of $F$. pinicola both in Matrigel tube formation and IP-10 release inhibition.

In conclusion, $R$. ulmarius have antiangiogenic and antiinflammation properties. We observe that different isolates of

Table 3

Composition of ethanolic extracts isolated from $R$. ulmarius.

\begin{tabular}{llll}
\hline Ethanolic extract $(\mathrm{mg} / \mathrm{g})$ & $\# 61$ & $\# 62$ & $\# 63$ \\
\hline Adenosine & $0.35 \pm 0.02$ & $1.05 \pm 0.01$ & $0.37 \pm 0.01$ \\
ADP & $2.19 \pm 0.03$ & $1.73 \pm 0.04$ & $6.61 \pm 0.19$ \\
Cytidine & $0.27 \pm 0.01$ & $0.41 \pm 0.02$ & $0.48 \pm 0.01$ \\
\hline
\end{tabular}

this fungal species possess different degrees of anti-inflammatory and antiangiogenic effects. To date, no reports are available in the literature regarding the cultivation, chemical constituents, or their biological functions. If, as in studies of some other mushrooms, living cultures will be of great interest for future studies to establish a scaleable method for commercial production.

\section{Acknowledgements}

We thank Dr. Tun-Tschu Chang, Division of Forest Protection, Taiwan Forestry Research Institute, Taipei, Taiwan for kindly supplying the isolates of R. ulmarius and Mr. D.P. Chamberlin for critically reading the manuscript. This work was supported by grants NSC96-2313-B-077-001-MY3 to MKL, and NSC97-2323-B077-002, NSC94-2320-B-077-011 to JJC from the National Science Council, Taiwan.

\section{Appendix A. Supplementary data}

Supplementary data associated with this article can be found, in the online version, at doi:10.1016/j.procbio.2009.06.018.

\section{References}

[1] Manzi P, Gambelli L, Marconi S, Vivanti V, Pizzoferrato L. Nutrients in edible mushroom: an inter-species comparative study. Food Chem 1999;65:47782.

[2] Yoshioka Y, Tabeta R, Saito H, Uehara N, Fukuoka F. Antitumor polysaccharide from P. ostreatus (FR.) Quél.: isolation and structure of a $\beta$-glucan. Carbohydr Res 1985;140:93-100.

[3] Kawagishi H, Kanao T, Mizuno T, Shimura K, Ito H, Hagiwara T. Formolysis of a potent antitumor $(1 \rightarrow 6$ )-beta-D-glucan protein complex from Agaricus blazei fruiting bodies and antitumoractivity of the resulting products. Carbohydr Polym 1990;12:393-403.

[4] Bohn J, BeMiller J. $(1 \rightarrow 3)-\beta$-D-glucan as biological response modifiers: a review of a structure-functional activity relationships. Carbohydr Polym 1995;28:3-14.

[5] Vetvicka V, Yvin J. Effects of marine $\beta-1,3$ glucan on immune reactions. Int Immunopharm 2004;4:721-30.

[6] Yoon S, Yu M, Pyun Y, Hwang J, Chu D, Juneja L, et al. The nontoxic mushroom Auricularia auricula contains a polysaccharide with anticoagulant activity mediated by antithrombin. Thromb Res 2003;112:151-8.

[7] Chu K, Ho S, Chow A. Coriolus versicolor: a medicinal mushroom with promising immunotherapeutic values. J Clin Pharmacol 2002;42:976-84.

[8] Chen L, Shao H. Extract from Agaricus blazei Murill can enhance immune responses elicited by DNA vaccine against foot-and-mouth disease. Vet Immunol Immunopathol 2006;109:177-82.

[9] Chen S, Lu M, Cheng J, Wang D. Antiangiogenic activities of polysaccharides isolated from medicinal fungi. FEMS Microbiol Lett 2005;249:247-54.

[10] Giatromanolaki A, Koukourakis M, O’Byrne K, Fox S, Whitehouse R, Talbot DC, et al. Prognostic value of angiogenesis in operable non-small cell lung cancer. J Pathol 1996;179:80-8.

[11] Giatromanolaki A, Sivridis E, Koukourakis MI, Georgoulias V, Gatter KC, Harris AL. Intratumoral angiogenesis: a new prognostic indicator for stage I endometrial adenocarcinomas? Oncol Res 1999;11:205-12.

[12] Koukourakis M, Giatromanolaki A, Fountzilas G, Sivridis E, Gatter K, Harris A. Angiogenesis, thymidine phosphorylase, and resistance of squamous cell head and neck cancer to cytotoxic and radiation therapy. Clin Cancer Res 2000;6:381-9.

[13] Aaronson D, Horvath C. A road map for those who don't know JAK-STAT. Science 2002;296:1653-5.

[14] Mach F, Sauty A, Iarossi A, Sukhova G, Neote K, Libby P, et al. Differential expression of three $\mathrm{T}$ lymphocyte-activating CXC chemokines by human atheroma-associated cells. J Clin Invest 1999;104:1041-50.

[15] Stemme S, Holm J, Hansson G. T lymphocytes in human atherosclerotic plaques are memory cells expressing CD45RO and the integrin VLA-1. Arterioscler Thromb 1992;12:206-11.

[16] Cheng J, Huang N, Chang T, Wang D, Lu M. Study for anti-angiogenic activities of polysaccharides isolated from Antrodia cinnamomea in endothelial cells. Life Sci 2005;76:3029-42.

[17] Cheng J, Lin C, Lur H, Chen H, Lu M. Properties and biological functions of polysaccharides and ethanolic extracts isolated from medicinal fungus. Fomitopsis pinicola. Process Biochem 2008;43:829-34.

[18] Fang Q. Effect of initial pH on production of ganoderic acid and polysaccharide by submerged fermentation of Ganoderma lucidum. Process Biochem 2002;37:769-74.

[19] Hsieh C, Hsua T, Yang F. Production of polysaccharides of Ganoderma lucidum (CCRC36021) by reusing thin stillage. Process Biochem 2005;40:909-16. 
[20] Cumashi A, Ushakova N, Preobrazhenskaya M, D'Incecco A, Piccoli A, Totani L, et al. A comparative study of the anti-inflammatory, anticoagulant, antiangiogenic, and antiadhesive activities of nine different fucoidans from brown seaweeds. Glycobiology 2007; 17:541-52.

[21] Matsubara K, Xue C, Zhao X, Mori M, Sugawara T, Hirata T. Effects of middle molecular weight fucoidans on in vitro and ex vivo angiogenesis of endothelial cells. Int J Mol Med 2005;15:695-9.

[22] Mourão P, Pereira M, Pavão M, Mulloy B, Tollefsen D, Mowinckel M, et al. Structure and anticoagulant activity of a fucosylated chondroitin sulfate from echinoderm: sulfated fucose branches on the polysaccharide account for its high anticoagulant action. J Biol Chem 1996;271:23973-84.
[23] Mourão P, Guimarães M, Mulloy B, Thomas S, Gray E. Antithrombotic activity of a fucosylated chondroitin sulfate from echinoderm: sulfated fucose branches on the polysaccharide account for its antithrombotic action. $\mathrm{Br} \mathrm{J}$ Haematol 1998;101:647-52.

[24] Pacheco R, Vicente C, Zancan P, Mourão P. Different antithrombotic mechanisms among glycosaminoglycans revealed with a new fucosylated chondroitin sulfate from echinoderm. Blood Coagul Fibrinolysis 2000;11:563-73.

[25] Ralevic V, Burnstock G. Receptors for purines and pyrimidines. Pharmacol Rev 1998:50:413-92.

[26] Burnstock G. Pathophysiology and therapeutic potential of purinergic signaling. Pharmacol Rev 2006;58:58-86. 